\title{
The End of My Term as Editor: Fostering Innovation and Nurturing an Intellectual Tradition
}

The publication of this volume (63) of Human Development marks the end of my editorial term that began in 2007. The present volume will include the first end of year special issue produced by the Jean Piaget Society (JPS) as part of the innovative agreement between the JPS and Karger Publishing. This connection with JPS is one of several innovations and exciting changes that took place during my time as editor. I inherited a treasure nurtured by the previous editor, Geoffrey Saxe, and his associate editor, Melanie Killen. They had continued the intellectual leadership that has made this journal the leading outlet for conceptual and theoretical work in our field.

I began my term as Editor with a wonderful Associate Editor, Terezinha Nunez of Oxford University. She produced special issues on the development of mathematical thinking and also on language development during the first three years of my term. I want to thank her for her scholarship, for maintaining the journal connections with scholars in Europe, and for her friendship and support.

Early in my editorial term we celebrated the 50th anniversary of this unique journal with a special issue that included classic articles published in Vita Humana (the original name of the journal) by Lawrence Kohlberg, and by Piaget, Wertsch and others under the Human Development banner along with companion articles by contemporary scholars updating the lines of theory contained in those classic works. It is entirely because of the personal investment of members of the Karger family, some of whom I had the privilege to work with, that this journal continues to thrive. I want to thank Thomas Karger and Gabriella Karger for their continual support. I want especially to honor the late Stephen Karger, who took a chance on me as editor.

As I began my term, Karger Publishing initiated an online platform for manuscript submissions. That revolutionized the editorial process, and Karger Publishing has continued to upgrade and improve that online platform. We also initiated several innovations in the journal itself. We established a semi-regular feature called “The Editor's Corner." This feature presents Op Ed style articles invited by the editor that address current topics and controversial issues in human development not generally addressed through articles in professional journals. The journal also initiated letters to the editor that allowed for ongoing discourse around issues raised in the published articles. Finally, as mentioned above, the journal is now the outlet for the annual JPS volume that emerges from their annual conference. This connection 
with JPS is due largely to the tireless efforts of the JPS publications editor, Nancy Budwig, and the support provided by Paul Lavender and Gabriella Karger of Karger Publishing.

I want to thank the scholars who comprise the editorial board for their wisdom in helping to shape journal policy and guide these innovations. Many of them also participated generously in the review process. The reviews of manuscript submissions to this journal are meticulous acts of scholarship in their own right, serving as guidance to authors through the revision process. The quality of the published articles is largely a function of the contributions of the reviewers. In this regard I want to express my thanks to the scholars who were not on the board who contributed generously of their time to produce these reviews.

I also want to express my gratitude to my wonderful editorial assistants, Marcy Hochberg (University of Illinois at Chicago), Alona Roded, Rebecca Anguiano, Deborah Powers, and Robyn Ilten-Gee (University of California, Berkeley). They enabled the review process to stay on track. They maintained communication with authors, reviewers, and members of the Karger staff. They also produced the initial phase of copy editing prior to submitting the manuscripts for production. It is their efforts and the incredible production staff at Karger Publishing in Basel that result in such a highquality journal issue after issue.

I am leaving the journal in very good hands with Susan Rivera of the University of California, Davis. Professor Rivera is a distinguished researcher in the field of $\mathrm{Hu}-$ man Development who brings a deep understanding of developmental theory, and a unique research focus on neuroscience and atypical development. The depth and breadth of her scholarship will allow her to honor the long-standing traditions of the journal, but also to expand the journal scope by extending it to the developmental neurosciences.

I want to end this essay as my predecessors have with a note of gratitude for the experience of serving as Editor of Human Development. This has been a labor of love. I have grown intellectually and professionally as a result of encountering the rich array of ideas produced by the authors and reviewers of the articles contained in the pages of this journal.

Larry Nucci, Editor in Chief 